\title{
CORRESPONDENCE
}

\author{
Diet and bowel cancer \\ R C N Williamson, \\ Delay in diagnosis in breast cancer \\ L Barr, MB, and M J Bailey, FRCs. . \\ Screening for the small-for-dates fetus \\ J $\mathbf{P}$ Neilson, $\mathrm{MB}$, and others........... \\ Family trends in psychotropic and \\ antibiotic prescribing in general \\ practice \\ C Bridges-Webb, MD. \\ Deaths from non-accidental injury \\ in children \\ Susan Creighton, MSC \\ Dorsal column stimulation in \\ multiple sclerosis \\ C H Hawkes, MD
}

Surgical treatment for prolapsed

lumbar disc

G O Tippett, FRCs............. 148

146 Infected hip prostheses

R E Loder, FFARCS.

147 Idiopathic carpal tunnel syndrome

J B Witcombe, FRCR; S Dekel, MD....... 148

Brachial plexus injuries in motorcyclists C B Wynn Parry, fRCs............... 149

Hypothyroidism in Down's syndrome

J C Murdoch, MD............... 149

Education, screening, and genetic counselling in thalassaemia

E Silvestroni, MD, and I Bianco, MD..... 149

Clinical use of nicotine chewing-gum

J R C West, MrCGP.............. 149
Delay in publishing ABPI Code of

Practice Committee rulings

G K Crompton, FRCPED............. 149

Earlier help for sick doctors

D F Robb, MRCs. ............... 150

Dental surgeons without medical

qualifications

P K B Davis, FRCs. . . . . . . . ........ 150

Cutting the cost of the National

Health Service

N G M Legg, FRCSED ............... 150

The Flowers Report and the Institute

of Dermatology

A P Warin, MRCP................ 150

A computer in every surgery?

C R Kay, FRCGP; A R Dewsbury, MRCGP . . 150

"Batch" or "on-line" for child health

M J G Thomas, MB............. 151

We may return unduly long letters to the author for shortening so that we can offer readers as wide a selection as possible. We receive so many letters each week that we have to omit some of them. Letters must be signed personally by all their authors. We cannot acknowledge their receipt unless a stamped addressed envelope or an international reply coupon is enclosed.

Correspondents should present their references in the Vancouver. style (see examples in these columns). In particular, the names and initials of all authors must be given unless there are more than six, when only the first three should be given, followed by et al; and the first and last page numbers of articles and chapters should be included. Titles of papers are not, however, included in the correspondence section.

\section{Diet and bowel cancer}

SrR,-Your leading article on the aetiology of colorectal carcinoma (31 May, p 1288) succinctly reviews the evidence for and against several dietary suspects: fat, fibre deficiency, meat, and alcohol. Taken singly, none of these agents makes an entirely convincing culprit, but each is compatible with the hypothesis that excess caloric intake is primarily to blame. ${ }^{1}$ Most epidemiological studies link the prevalence of intestinal cancer to the economic affluence of a population. Both fat and fibre produce satiety; fatty foods are generally tastier but more expensive. Therefore wealthy communities prefer to eat fat and grow fat. Meat is a major source of animal fat, and alcohol provides calories aplenty but no residue.

The correlation between increased body weight and cancer in general is quite well established in both man and experimental animals $^{23}$ and may hold true for colon cancer, though published data are scanty. ${ }^{1}$ Increased cell turnover in colonic crypts could explain the promotion of carcinogenesis by ulcerative colitis, irradiation, and ileal resection. Intestinal mucosa is disproportionately sensitive to fluctuations in oral intake of nutrients. Fasting depletes both small and large bowel of epithelial cells ${ }^{5}$; as a corollary, since over-eating causes enteric hyperplasia $^{6}$ it probably increases colonic cell proliferation as well. Obesity is also accompanied by greater faecal excretion of bile acids, and these act directly as cocarcinogens in rat intestine. ${ }^{7}$ Moreover, jejunoileal bypass (as performed for obesity in man) appears to reduce the yield of experimental colorectal cancers. ${ }^{8}$
Prospective studies to determine the body weight and dietary habits of patients with large-bowel cancer are urgently needed to unravel the causes of this latter-day scourge.

\section{University Department of Surgery,}

ROBIN WILLIAMSON Bristol Royal Infirmary, Bristol BS2 8HW

${ }^{1}$ Heaton KW. In: Truelove SC, Lee E, eds. Topics in Gastroenterology, vol 5. Oxford: Blackwell, 1977 29-45.

2 Clayson DB. Cancer Res 1975; 35 :3292-300.

Tannenbaum A. Arch Pathol 1940;30:509-17.

Oscarson JEA, Veen HF, Ross JS, Malt RA. Ann Surg 1979;189:503-8.

Hagemann RF, Stragand JJ. Cell Tissue Kinet 1977;

6 Williamson RCN. N Engl f Med 1978;298:1393-1404. Narisawa T, Magadia NE, Weisburger JH, Wynder EL. $\mathcal{O}$ Natl Cancer Inst 1974;53:1093-7

Williamson RCN, Bauer FLR, Terpstra OT, Ross JS, Malt RA. Cancer Res 1980;40:538-43.

\section{Delay in diagnosis in breast cancer}

SIR,-We read with interest the paper from Vancouver by Drs J Mark Elwood and William P Moorehead (31 May, p 1291) demonstrating that a shorter history from the first symptom of a breast carcinoma to its diagnosis was associated with a better survival rate even when calculated from the date of the first symptom. Their conclusion was that public education to present earlier with breast symptoms would therefore improve survival.

However, while agreeing with this plea for public education to persuade women to present earlier, we are reluctant to accept their conclusion that overall survival could thereby be improved. The argument that moving patients from the "long-delay" category into the "short-delay" category would improve their survival is based on the assumption that factors other than diagnostic delay are equal within these groups, and ignores the possibility that other aspects of patient or tumour behaviour may introduce a selection bias. The evidence that earlier diagnosis improves survival is still not convincing and it seems likely that dissemination of disease beyond the breast may occur before the appearance of the first symptom, let alone diagnosis. ${ }^{1}$ If this is the case, then the basis of our plea for earlier diagnosis is not that we can thereby control systemic disease but rather that we can control local disease with less radical surgery.

In 1979, 105 new cases of breast carcinoma presenting to our combined breast clinic have been reviewed to compare length of history with tumour diameter as measured by the pathologist and with type of operation performed. The surgical policy was to manage medial tumours by wide local excision with radical postoperative radiotherapy. From the accompanying table it can be seen that patients with a shorter history tended to have smaller tumour diameters and a higher proportion of the tumours considered suitable for conservative surgery.

A preliminary analysis of the results of our trial comparing wide local excision and postoperative radiotherapy with total mastectomy for patients with medial tumours shows no significant difference in the incidence of local recurrence (paper in preparation). Because of this we have extended our policy to include patients with lateral tumours as being suitable for wide local excision and 
Size of tumour and operation performed in relation to length of history, 1979

\begin{tabular}{lccc}
\hline & $\begin{array}{c}\text { Short* } \\
\text { history }\end{array}$ & $\begin{array}{c}\text { Intermediate } \\
\text { history }\end{array}$ & $\begin{array}{c}\text { Long† } \\
\text { history }\end{array}$ \\
\hline No of inoperable & 1 & 2 & 7 \\
$\begin{array}{c}\text { tumours } \\
\text { diameter }(\mathrm{cm})\end{array}$ & $1 \cdot 6$ & $2 \cdot 6$ & $3 \cdot 1$ \\
$\begin{array}{l}\text { No of } \\
\text { mastectomies }\end{array}$ & 19 & 29 & 8 \\
$\begin{array}{c}\text { No of wide local } \\
\text { excisions }\end{array}$ & 16 & 22 & 1 \\
\hline $\begin{array}{l}\text { Total No of } \\
\text { patients }\end{array}$ & 36 & 53 & 16 \\
\hline
\end{tabular}

*Short history $\leqslant$ one month

tLong history one year.

radiotherapy. The selection of patients for conservative surgery is on the basis of the relative volume of the tumour to the breast and on its position. Patients with central tumours still undergo mastectomy but patients with relatively small medial or lateral tumours have wide local excision.

If wide local excision and postoperative radiotherapy can control local disease as effectively as mastectomy, then our message to the public is not that shorter delay necessarily means longer survival but that shorter delay means less radical surgery.

We thank Drs J C Gazet, $\mathrm{H}$ T Ford, and T J Powles of the St George's Hospital combined breast clinic at the Royal Marsden Hospital for permission to review their patients.

LESTER BARR Michael BaIley

Royal Marsden Hospital,

1 Tubiana M, Chauvel P, Renaud A, Malaise EP. Bull Cancer $1975 ; 62: 341-58$.

\section{Screening for the small-for-dates fetus}

SIR,-We thank Dr R H Klipstein (21 June, $p$ 1534) for his interest in our two-stage ultrasonic examination schedule to screen for intrauterine growth retardation, which, using the crown-rump length $\times$ trunk area index detected $94 \%$ of small-for-dates fetuses in almost 500 singleton pregnancies (17 May, p 1203) and which we are now subjecting to a prospective controlled tiral. However, we cannot agree that the efficacy of a screening procedure can be equated solely with its predictive value (defined as the ratio of truepositive to false-positive diagnoses). Rather we believe that its efficacy must also take into account sensitivity (defined as the ratio of true-negative to false-negative results) and clinical usefulness.

We made the point that false-negative results (that is, undetected growth retardation) are of greater practical significance than falsepositives and we therefore viewed the crownrump length $\times$ trunk area index (falsenegative rate $6 \%$, false-positive rate $12 \%$ ) as more useful than the crown-rump length $\times$ trunk circumference index (false-negative rate $11 \%$, false-positive rate $.9 \%$ ). Many false-positives can be identified as such by further detailed ultrasonic examination following a screening diagnosis of growth retardation. Indeed, further management (including intervention) would depend, as we stated, on further intensive biophysical and biochemical monitoring and also, of course, on continued clinical surveillance. It is also relevant that half our false-positives related to babies with birth weights below the 10th percentile (sometimes taken as the cut-off point defining growth retardation) but above the 5 th percentile (our cut-off); it seems to us no great harm that these fetuses in particular should be subjected to investigation of their subsequent growth and wellbeing.

Thus we can reassure Dr Klipstein that there need be no undue concern that our chosen screening parameter will necessarily lead to more unnecessary intervention than would the use of the crown-rump length $\times$ trunk circumference index.

J P NEILSON

C R WHITFIELD

TOM AITCHISON

University Department of Midwifery,

Queen Mother's Hospital,
Glasgow G3 8SH

Family trends in psychotropic and antibiotic prescribing in general practice

SIR,-The paper by Drs J G R Howie and A R Bigg (22 March, p 836) is a further useful addition to the relatively small amount of information about prescribing in general practice. It is of interest, however, that the authors did not consider the possibility that the children of anxious mothers actually do have more respiratory diseases requiring antibiotics than the children of mothers not so anxious.

There is also little comment on the finding that anxious mothers most often need psychotropic drugs while the children are young or while they are approaching puberty. Such a finding is perhaps not unexpected and might also tie in with the finding that mothers with more children are less likely to be high users of psychotropic drugs. These findings would reinforce the author's suggestions that family structure and dynamics may well be an important influence in prescribing.

\section{BRIDGES-WEBB}

University Department of Community Medicine, Sydney 2006, Australia

\section{Deaths from non-accidental}

\section{injury in children}

SIR,-I would concur with Dr J A Baldwin's estimate (21 June, $p$ 1533) that the number of children who die annually from non-accidental injury is considerably higher than the Registrar General's figure for "deaths due to homicide and injury purposely inflicted by other persons," as was suggested by Dr K T Farn (3 May, p 1145).

There are three aspects to deaths from this cause which merit consideration. Firstly, nonaccidental injury occurs almost exclusively in the home in the absence of independent witnesses. Secondly, the injuries sustained may not be the immediate cause of death. Thirdly, some deaths due to non-accidental injury get misdiagnosed.

When a child dies in suspicious circumstances, the parents deny deliberately injuring it, and the medical evidence cannot determine conclusively that the injuries had been purposely inflicted the coroner has no option but to record an "open verdict." With nine of the 21 dead children in the sample of battered children reported by Smith and Hanson, the coroner had reached this verdict. ${ }^{1}$ These "open verdict" deaths are recorded by the Registrar General under the category "injury undetermined whether accidentally or purposely inflicted." In 1977 the number of child deaths recorded in this category ${ }^{2}$ was $30-a$ figure which when added to the 78 homicides in that year exceeds Dr H B Valman's estimate (15 March, p 775).

There are also the cases where the inflicted injuries do not cause death in themselves but so weaken the child's resistance to infections as to lead to death from. "natural causes." In 1975 nine dead children were referred to the Registers of Suspected Non-Accidental Injury maintained by NSPCC Special Units ${ }^{3}$ in five different parts of the country. Two of these children were recorded as having died of bronchopneumonia, one with 106 bruises of different ages on her body; both mothers were prosecuted for assault. Two of the other dead children (siblings) had originally been diagnosed as cases of cot death. It was not until their healthy $4 \frac{1}{2}$-year-old brother died in the same manner that their deaths were reexamined. Half of Johnson's 17 cases of battered babies, originally thought to have died of natural causes, had been diagnosed as cases of cot death. ${ }^{4}$ It would seem that cases where the attending doctor misdiagnoses the cause of death are not as uncommon as one might expect.

Susan Creighton

National Society for the Prevention of Cruelty to Children,

1 Smith SM, Hanson R. Br Med $\mathcal{f} 1974$;iii :666-70. 2 Office of Population Censuses and Surveys. Mortality statistics: childhood and maternity 1977. London

HMSO, 1979.
s Creighton SJ, Owtram PJ. Child victims of physical abuse. London: National Soci

4 Johnson HRM. Med Sci Law 1969; April: 102-6.

\section{Dorsal column stimulation in multiple} sclerosis

SIR,-Your leading article (31 May, p 1287) presents a very reasonable assessment of the current state of affairs with regard to dorsal column stimulation in multiple sclerosis. The statement, however, that there is "total lack of any data showing how the treatment works" is too sweeping. Data exist but hard facts do not. Any proposition needs to explain why dorsal column stimulation will help "central" pain and bladder function and why the effect on micturition is insidious, usually maximal at six to seven days, wearing off equally slowly. ${ }^{1}$ This favours a more hormonal than an electrical effect, although both may be responsible.

The fragmentary data relating to mechanism are: (1) Dorsal column stimulation elevates adrenaline, noradrenaline, and dopamine in plasma and noradrenaline in cerebrospinal fluid. ${ }^{2}$ (2) There is no change in CSF homovanillic acid or 5-hydroxyindole-acetic acid. ${ }^{3}$ (3) Dorsal column stimulation reduces urethral sphincter tone, ${ }^{4}$ which suggests $\alpha$-sympatholytic or parasympathomimetic action. (4) Dorsal column stimulation has no effect on or possibly depresses CSF met-enkephalin levels. It is possibly naloxone reversible. ${ }^{1}$ (5) It has evoked potentials ${ }^{5}$ and $H$ responses. ${ }^{6}(6)$ It has improved leg blood flow. ${ }^{7}$ Observations 1-6 are based on very small numbers. The possibility that a neuropeptide or prostaglandin is involved needs close scrutiny.

The overwhelming problem in multiple sclerosis is how to disentangle possible benefits 